\title{
Noise Exposure Level of Coal-Fired Thermal Power Stations in Different Scales — China, 2017-2019
}

\author{
Xin Wang'; Siyu Zhang'; Ning Kang'; Weijiang $\mathrm{Hu}^{1, *}$
}

\section{Summary}

What is already known about this topic?

China is a country mainly based on thermal power generation. Noise is one of the most critical occupational hazards among thermal power stations.

What is added by this report?

The proportion of detected environmental noise that exceeded $85 \mathrm{~dB}(\mathrm{~A})$ is $69.6 \%$, and the median of its noise level was $88.4 \mathrm{~dB}(\mathrm{~A})$. The proportion of detected individual noise that exceeded $85 \mathrm{~dB}(\mathrm{~A})$ was $52.6 \%$, and the median of its noise level was $85.4 \mathrm{~dB}(\mathrm{~A})$. The overall environmental noise exposure levels rose with the increase in the scales of coal-fired thermal power stations, while the individual noise exposure levels were contrary.

What are the implications for public health practice?

Workers in coal-fired thermal power stations are exposed to noise at a significantly high level, more than half of the environmental and individual exposure level were above $85 \mathrm{~dB}(\mathrm{~A})$, which could impair workers' hearing capacity. Specific intervention is required to protect workers from exposure to noise at the workplace and eliminate the adverse health effects.

China has become the world's largest producer of electricity in which thermal power generation remains a major source of power (1-2). In 2018, the total electricity generated in China was 7.1 trillion kilowatthours (kWh), of which electricity generated by thermal power generation was 5.1 trillion $\mathrm{kWh}$, accounting for $71.8 \%$ of the total (3). At the end of 2018, China's installed power generation capacity was 190.0 million kilowatts and installed thermal power generation capacity was 114.4 million kilowatts (kW) (4), accounting for $60.2 \%$ of the total. Noise is one of the most critical occupational hazards among thermal power stations and can result in occupational noiseinduced deafness and other adverse health effects (5-6). With the development of science and technology, thermal power plants have gradually transformed from 300 megawatt (MW) units to 600 MW and 1,000 MW units, and the noise hazards have become more prominent and complicated. A total number of 588,041 workers were engaged in electrical, gas, and sanitation services in the United States, of which $15.3 \%$ of workers are exposed to noise above 85 $\mathrm{dB}(\mathrm{A})$ (7), while the number of workers exposed to high noise-levels is likely higher in China. In recent years, the total number of cases of occupational noiseinduced deafness was around 1,400 per year in China, and 20-30 cases were from thermal power stations. This study presented an analysis of the exposure data of noise from nine coal-fired thermal power plants to understand the noise intensity in the workplace and the personal noise exposure levels among workplaces of different sizes and provide scientific evidence for controlling the hazards.

A total of 9 coal-fired thermal power stations were selected to conduct occupational health surveys and noise detection of a total of 20 power generating units including 2 units of $2 \times 300 \mathrm{MW}, 3$ units of $2 \times$ $600 \mathrm{MW}, 1$ unit of $4 \times 600 \mathrm{MW}, 1$ unit of $2 \times 660 \mathrm{MW}$, and 2 units of $2 \times 1,000 \mathrm{MW}$. The units were divided into 3 categories according to their ability: subcritical (300 MW), supercritical (600 MW), and ultrasupercritical (660 MW and 1,000 MW).

Occupational health surveys had been conducted for each thermal power station to gather the basic information of the power stations, production process, positions and number of workers exposed to noise, inspection routes of each position, and distribution of main noise-causing equipment. The sampling method and noise detection method were determined based on the Measurement of Physical Agents in the Workplace Part 8: Noise (GBZ/T 189.8-2007).

This study investigated both environmental and individual noise exposure based on the major production units of the stations including coal transportation, combustion systems, thermal systems, ash handling systems, flue gas desulfurization, and chemical water treatment. Levels of environmental noise on-site were measured using the AWA5633A 
sound level meter with a frequency range of $20 \mathrm{~Hz}-8$ $\mathrm{kHz}$, detection interval of 1 second, weight of $\mathrm{A}$, slow gear of $S, 3$ times for each detection point and average value. Individual noise exposure levels were measured by QUEST NoisePro personal noise dosimeter, with a frequency range of $20 \mathrm{~Hz}-8 \mathrm{kHz}$ and a detection interval of $1 \mathrm{~s}$. For each post, 1-2 people were selected to detect 3 shifts, and the average value was taken.

According to the Occupational Exposure Limits for Hazardous Agents in the Workplace Part 2: Physical Agents (GBZ 2.2-2007), 8 hours of exposure to an equivalent sound level $\left(\mathrm{L}_{\text {Aeq.8h }}\right)$ equal to or greater than $85 \mathrm{~dB}(\mathrm{~A})$ is considered as exceeding the standard for both environmental and individual noise exposure. Statistical analysis was performed using SPSS (version 22.0, SPSS Inc, Chicago, IL, USA). The median and inter quartile range (IQR) were calculated to describe the distribution of the noise exposure level, and Fisher's exact test was applied to analyze environmental and individual noise exposure levels among coal-fired thermal power stations in different scales. The statistical difference was considered significant when $p<0.05$.

A total of 2,123 environmental noise samples were detected in coal-fired power stations of different scales (Table 1). The medians of the overall environmental noise exposure in all scales of stations were above 86 $\mathrm{dB}(\mathrm{A})$. Both the median of the environmental noise and the proportion of environmental noise that exceeded the legislated occupational exposure limit $(\mathrm{OEL})$ value of $85 \mathrm{~dB}(\mathrm{~A})$ rose with an increase in the scales of coal-fired thermal power stations. Overall, the median of environmental noise exposure in thermal system was $89.7 \mathrm{~dB}(\mathrm{~A})$, which was the most serious among all types of stations. The environmental noise levels in the combustion systems and ash handling systems in ultra-supercritical stations, $90.7 \mathrm{~dB}(\mathrm{~A})$ and $91.5 \mathrm{~dB}(\mathrm{~A})$, respectively, were higher when compared to smaller stations. A decrease in noise exposure was found in the chemical water treatment units when the station scale was larger.

The main mode of workers in the coal-fired thermal power stations was inspection work mode. There were twice inspections per shift for each unit. Each inspection time was about 1.5-2 hours in ultrasupercritical stations, $2-3$ hours in supercritical stations, 3-4 hours in subcritical stations. Table 2 showed worker's $\mathrm{L}_{\text {Aeq. } 8 \mathrm{~h}}$ which served as parameters for individual noise exposure level in different scales of coal-fired thermal power station. The median of overall individual noise exposure level at ultra-supercritical stations $[84.3 \mathrm{~dB}(\mathrm{~A})]$ was the lowest, while the median at supercritical stations $[86.0 \mathrm{~dB}(\mathrm{~A})]$ was the highest. The overall individual noise exposure was at the lowest level in the ultra-supercritical stations. On the contrary, the median of $\mathrm{L}_{\text {Aeg. } 8 \mathrm{~h}}$ in flue gas desulfurization systems $[87.8 \mathrm{~dB}(\mathrm{~A})]$ was significantly higher among the ultra-supercritical stations compared to low-scale stations. The individual noise exposure in the chemical water treatment systems in ultrasupercritical stations $[83.2 \mathrm{~dB}(\mathrm{~A})]$ was higher than the levels in subcritical stations [79.6 $\mathrm{dB}(\mathrm{A})]$, but was lower than supercritical stations $[85.6 \mathrm{~dB}(\mathrm{~A})]$.

\section{DISCUSSION}

A high level of exposure to occupational noise remains in many workplaces, which results in a major burden that has been consequential worldwide (8). As described above, both the environmental and individual noise-exposure levels exceeded the national standard of acceptability in many areas among stations in all stations due to the large number of pumps, fans, compressors, and other equipment. The high prevalence of high-frequency and speech-frequency hearing impairments among workers had been demonstrated in power stations with a similar level of noise exposure as used in our study (9). With increasing capacity of coal-fired thermal power stations, environmental noise levels had noticeably increased. Noise hazards among the combustion systems, thermal systems, ash-handling systems, and flue gas desulfurization systems should be considered at a high priority because of their intensity in all scales of thermal power stations. These systems often included more high-noise equipment, and the compact distribution of this equipment resulted in noise stacking that also increased the noise hazards. This was also shown in a study from Tanzania which suggests that the average individual noise-exposure level of workers was $91.4 \pm 11.6 \mathrm{~dB}(\mathrm{~A})$ among gas-fired thermal power stations that shared similar thermal system processes as coal-fired thermal power stations (10).

However, the positive results found in this study showed the actual personal noise-exposure levels to workers during their work time were reduced in ultrasupercritical stations. The ultra-supercritical thermal power stations were built in recent years with more advanced technology, and the level of automation of machines was higher when compared to subcritical and supercritical stations that resulted in shorter inspection time for the workers. We also found the personal 


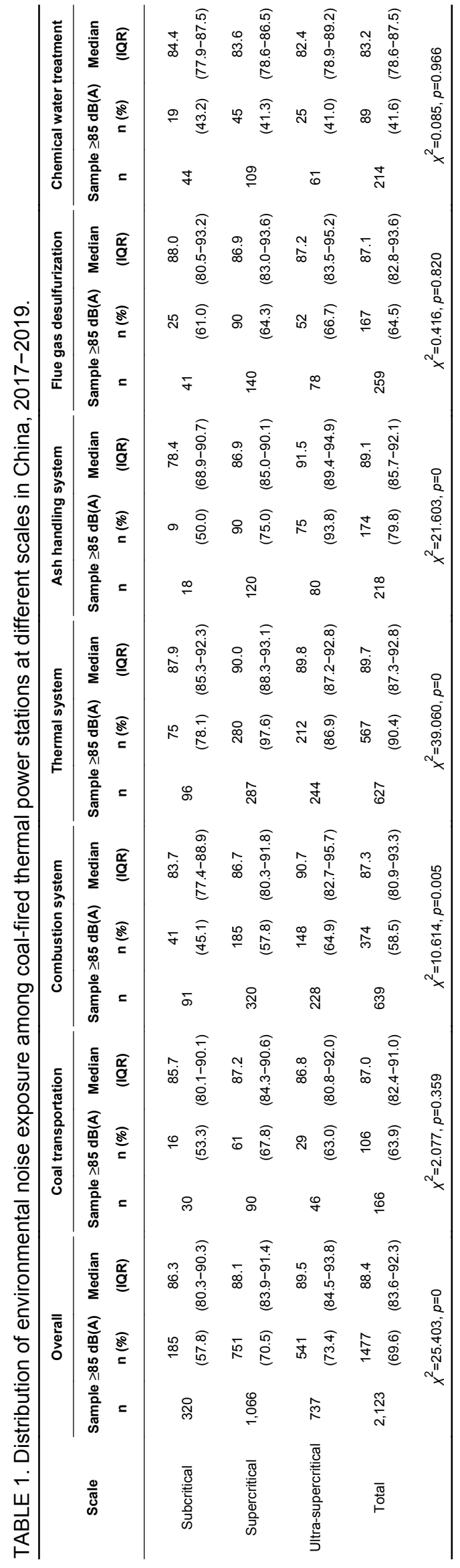

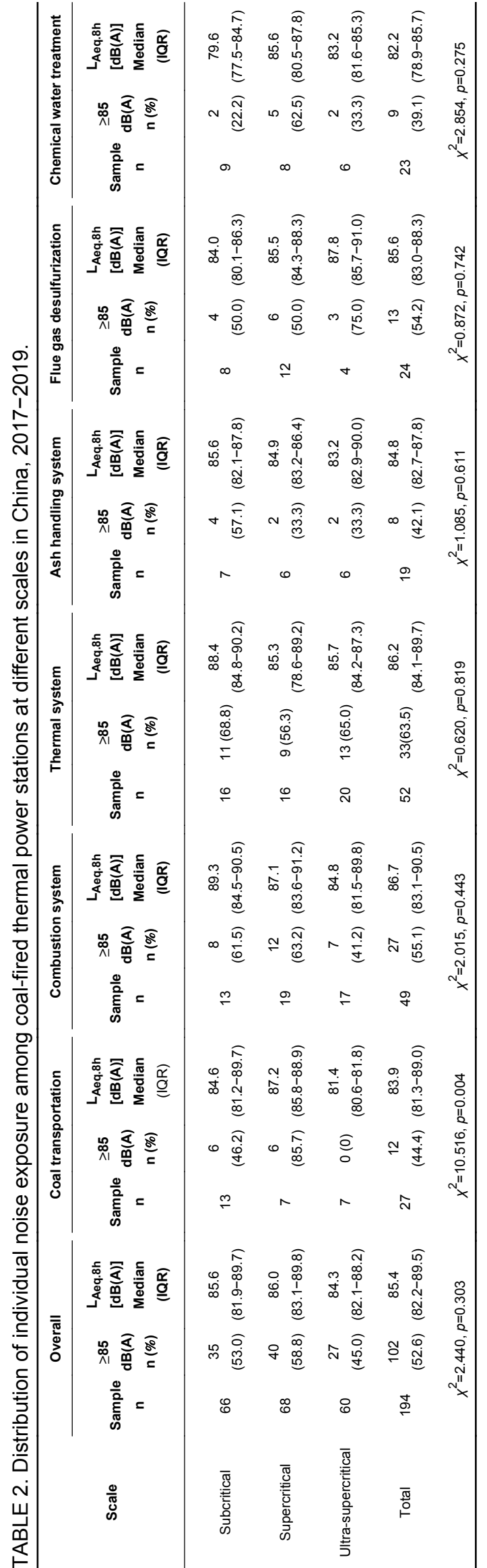


$\mathrm{L}_{\text {Aeq.8h }}$ from the flue gas desulfurization system was higher in ultra-supercritical stations than those among stations in smaller scales, although the inspection time was shorter. This was likely due to mandatory inspection times for several workplaces with high noise exposure, such as inspecting booster fans and oxidation air fans.

Preventing and controlling both environmental and individual occupational noise exposure has remained a major challenge for a long time as high levels of noise exposure remain in coal-fired thermal power stations across China. Developing and implementing effective and efficient measures, especially technical measures, to reduce noise hazards and protect workers' health and wellbeing is crucial even in technologically advanced thermal power stations. For subcritical and supercritical stations, improving the production processes and implementation of automation could be considered to reduce the intensity of noise generated from industrial equipment. In terms of the industrial equipment that generates noise at a high intensity, engineering control measures should be taken such as sound dampening or adding sound insulation, or these high-noise environments can be visited sparingly on the inspection route.

Occupational health regulations should be established to enhance occupational health training and supervision of wearing personal hearing protection. Regular occupational health examinations should be provided for workers, especially for those who were exposed to noise above $95 \mathrm{~dB}(\mathrm{~A})$ such as those working in combustion systems and flue gas desulfurization systems in ultra-supercritical coal-fired thermal power stations.

The findings in this report were only concerning the exposure level of environmental and individual exposure level, and related health data which could be affected by noise among the workers were not involved. Further studies will be conducted to investigate the relationship between noise exposure and related health consequences among coal-fired thermal power stations at different scales. This study was subject to three limitations. First of all, personal protective equipment was not considered, which may have a certain impact on assessing the actual noise exposure level of workers. Secondly, this study was a cross-sectional survey, and was cautious about the causal relationship between occupational noise and relevant risk factors. Third, the research objects came from selected coal-fired thermal power stations only, and the generalization of the findings may be limited.

Acknowledgment: We thank all participants and professional technical staff.

Funding: This study was supported by the Noise Occupational Health Risk Assessment Project (No.13103110900015003).

Conflict of Interests: No conflicts of interest were reported.

doi: $10.46234 / \mathrm{ccdcw} 2020.164$

\# Corresponding author: Weijiang Hu, Huwj@niohp.chinacdc.cn.

${ }^{1}$ National Institute of Occupational Health and Poison Control, Chinese Center for Disease Control and Prevention, Beijing, China.

Submitted: April 14, 2020; Accepted: July 21, 2020

\section{REFERENCES}

1. Yan YL, Peng L, Li RM, Li YH, Li LJ, Bai HL. Concentration, ozone formation potential and source analysis of volatile organic compounds (VOCs) in a thermal power station centralized area: a study in Shuozhou, China. Environ Pollut 2017;223:295-304. http://dx.doi.org/10. 1016/j.envpol.2017.01.026.

2. Company BP. BP statistical review of world energy. 2019. https://www.bp.com/content/dam/bp/business-sites/en/global/corporate/ $\mathrm{pdfs} /$ energy-economics/statistical-review/bp-stats-review-2019-fullreport.pdf. [2020-07-21].

3. National Bureau of Statistics. Chapter VII of the fourth national economic census series report. http://www.stats.gov.cn/tjsj/zxfb/ 201912/t20191209_1716475.html. [2019-12-9]. (In Chinese).

4. National Bureau of Statistics. National economic and social development statistical bulletin 2018. http://www.stats.gov.cn/tjsj/zxfb/ 201902/t20190228_1651265.html. [2019-2-28]. (In Chinese).

5. Zhou SY, Wen XZ, Li XD, Wen CJ, Li WH. Epidemiological characteristic analysis on occupational noise-induced deafness in Guangdong Province, 2011-2015. China Occup Med 2017;44(6): 737 - 9, 744. https://kns.cnki.net/KCMS/detail/detail.aspx?dbcode= CJFQ\&dbnameCJFDLAST2018\&filenam =XYYX201706021\&vMjkz NjIxTHV4WVM3RGgxVDNxVHJXTTFGckNVUjdxZmIrWnJGQ3 ZoVkw3QVBUVFNkckc0SDliTXFZOUhaWVI4ZVg=. (In Chinese).

6. Cao YQ, Ta H, He L, Liao HX, Lan YJ, Shang WW. Analysis of the characteristics of occupational noise deafness in Sichuan province from 2006 to 2016. Mod PrevMed 2018;45(8):1372 - 5. http://d.wanfangdata. com.cn/periodical/xdyfyx201808007. (In Chinese).

7. The National Institute for Occupational Safety and Health (NIOSH). Occupational noise exposure. 1998. https:/www.cdc.gov/niosh/docs/ 98-126/. [2020-07-21].

8. GBD 2016 Occupational Risk Factors Collaborators. Global and regional burden of disease and injury in 2016 arising from occupational exposures: a systematic analysis for the Global Burden of Disease Study 2016. Occup Environ Med 2020;77(3):133 - 41. http://dx.doi.org/10. 1136/oemed-2019-106008.

9. Tang CZ, Sun M, Zhu T, Liu J. Investigation on the health status of the workers exposing to noise in a power plant. Mod Prev Med 2009;36(12): 2253 - 4, 2261. https://kns.cnki.net/kcms/detail/detail. aspx?filename=XDYF200912021\&dbcodeCJFQ\&dbnameCJFD2009\&v. (In Chinese).

10. John W, Sakwari G, Mamuya SH. Noise exposure and self-reported hearing impairment among gas-fired electric plant workers in Tanzania. Ann Glob Health 2018;84(3):523 - 31. http://dx.doi.org/10.29024/ aogh.2305. 